Article

\title{
Christians' Perceptions of Receiving Spiritual Care in the Bible Belt of the United States: A Qualitative Study of Care Provided in the Healthcare Setting
}

\author{
Liz McDowell * (D) and Robbie Madden South \\ Nursing, Lander University, 320 Stanley Avenue, Greenwood, SC 29649, USA; rsouth@lander.edu \\ * Correspondence: lmcdowell@lander.edu; Tel.: +1-864-421-7788
}

Received: 13 June 2017; Accepted: 10 July 2017; Published: 13 July 2017

\begin{abstract}
The need to include the spiritual dimension when assessing clients and planning their healthcare is evident from numerous studies conducted by various disciplines. Practitioners of holistic care agree that spiritual care must be included to address fully the needs of clients. The aim of this qualitative research was to explore and document the stories of clients regarding the role healthcare professionals provide in spiritual care. A hermeneutical phenomenological approach was used to interview, document, and analyze the stories of 15 participants $(n=15)$ regarding their perceptions of spiritual care received or given during times of illness. Initially, only one participant mentioned the role of doctors and nurses in providing spiritual care. After specifically asking about spiritual care, half of the participants shared that they had received spiritual care. Prayer as a mode of spiritual care emerged as a prominent theme. Lack of spiritual care received was documented. The hesitancy to provide spiritual care was evident in participants who were also healthcare providers. More research is needed to further define spiritual care. Education regarding spiritual assessments and spiritual care strategies is needed for both patients and healthcare providers.
\end{abstract}

Keywords: spiritual care; spirituality; nursing; healthcare providers; spiritual assessments; prayer; healing

\section{Introduction}

Florence Nightingale, the founder of modern nursing, left a rich legacy of spirituality in nursing practice and based many of her views on a spiritual philosophy (Mowdy 2006). Historically, nurses accepted their service to the sick as a calling and a ministry. Many of the early schools of nursing were affiliated with the religious institutions of their day. Spirituality has been recognized as a human need throughout the history of nursing (O'Brien 2008; Taylor 2002). Spiritual care, though not fully understood by all health care providers, is a necessary component of holistic nursing practice (South 2017, p. 63). Although nurses often recognize the efficacy of spiritual interventions, many nurses feel inadequate to address spiritual needs and therefore, omit spiritual care (Dossey and Keegan 2016; Grant 2004; Ledger 2005).

Holistic nursing care incorporates the needs of body, mind, and spirit. The spiritual dimension, in a bio-psycho-social-spiritual model, considers a person's values and meaning in life; and may include the concept of transcendence, which suggests a guiding force outside of self and a belief in God or a higher power (Dossey and Keegan 2016; Neuman and Fawcett 2002). Persons considered whole, or healthy, must be well in the realm of the spirit as well as the body and mind. Holistic nursing care must include a spiritual assessment and therapeutic interventions ( $\mathrm{O}^{\prime}$ Brien 2008), with respect to a client's personal preferences and belief system (Winslow and Winslow 2003).

Spirituality has received increased attention in the professional literature in recent years. A search of literature related to spirituality or spiritual care provides a plethora of related articles. Disciplines 
outside of nursing, such as psychology and sociology, support the concept of spiritual care for individuals facing health-related problems (Taylor 2002). The need to include the spiritual dimension when assessing and planning care for clients is evident from numerous studies conducted by various disciplines. Health care providers throughout the world are addressing this need.

Taheri-Kharameh et al. (2016) conducted a cross-sectional study in 2014 with 55 nurses in an intensive care unit of an educational hospital in Qom, Iran to determine the attitude of intensive care nurses toward spirituality and spiritual care and its relationship with mental health. The authors suggest that spiritual care is essential to nursing care and plays an effective role in the overall health and wellbeing of patients. They noted that nursing education in religious or spiritual activities is essential to strengthen spiritual care provision to patients.

Ebrahimi et al. (2017) conducted cross-sectional analytical research with 555 nurses in 2014 in Iran to examine their perception of competence in providing spiritual care to their patients. Although the nurses' competence in providing spiritual care was average, the authors concluded that spiritual care competence in education and training should be considered in nursing curricula.

Hodge and Horvath (2011) conducted a meta-synthesis examining clients' perceptions of spiritual care in the healthcare setting. The authors identified that spiritual needs are prevalent in healthcare settings, but often inadequately addressed. The findings indicated a need for education for social workers regarding spirituality, spiritual assessments, and strategies for spiritual care.

Hodge and Wolosin (2014) conducted a secondary analysis of inpatient satisfaction data from Press Ganey Associates to explore the pathways that account for positive relationships between satisfaction with service provision and the delivery of spiritual care. Their analyses concluded that nurses play a central role in the relationship between spiritual needs and patients 'satisfaction of care provided. The results also indicated that frontline hospital personnel such as nurses and physicians should address spiritual needs and not solely delegate these needs to clergy or chaplains.

Canfield et al. (2016) conducted interviews with 30 nurses in a mid-western teaching hospital in the United States to determine their definitions of spirituality, their comfort in providing spiritual care, and their perceived need for education in providing the care. Their findings indicated that although nurses generally feel comfortable providing spiritual care, they expressed a need for additional education related to multicultural considerations.

Tanyi et al. (2009) conducted semi-structured interviews of three physicians, five nurse practitioners, and two physician assistants to examine how they incorporate spiritual care into their family practice. The findings indicated that spiritual care was being provided; however, one identified barrier was the lack of formal training or education in spiritual care.

Puchalski et al. (2014) reported on conferences held in 2012 and 2013 with goals of reaching consensus on strategies for integrating spiritual care into health care at all levels and approaches for creating compassionate systems of care. The need for education of health care workers was recognized with a recommendation that curricula should be created that covered definitions of spirituality, self-awareness, cultural sensitivity, and skills in assessment of spirituality.

Spiritual care has roots in historical examples of caring for the sick. Practitioners of holistic care and nursing theorists agree that spiritual care must be included to address fully the needs of patients. As frontline care providers, nurses are important providers of spiritual care and are positioned to assess and address the spiritual needs of patients. Research studies indicate that nurses and other disciplines may be providing spiritual care, but feel limited by barriers such as lack of education in spiritual care strategies. A literature review shows that the global healthcare community is addressing the spiritual needs of patients and exploring the views of patients and healthcare providers. This article will discuss interviews with both patients and healthcare providers and will include their perceptions of the provision of spiritual care. This topic is of particular interest to educators of various healthcare providers, accreditation agencies, researchers, and active practitioners; however, is most significant for nurses. This research is primarily focused on the spiritual care provided by nurses. 


\section{Materials and Methods}

The aim of this qualitative research is to explore and document participants' stories of the role healthcare professionals provide in spiritual care. This analysis is a secondary examination of a larger study conducted by the same co-investigators. The aim of the larger study was to document participants' stories of miraculous or mysterious healings. Therefore, the participants $(n=15)$ were initially asked to tell their stories of healings. Because four of the participants who shared stories of healing were healthcare professionals, we were able to inadvertently record their stories from two perspectives-that of both the giver and receiver of spiritual care. Realizing this is a small sample, we still felt their stories were important to share as part of this manuscript.

The co-investigators are both nurses who teach nursing at a small liberal arts university in the southeastern United States. Both co-investigators practice the Christian faith and have experienced healings in their personal lives. Robbie Madden South is a professor emeritus and former school of nursing director. Her primary nursing foci include community health nursing and spiritual care. Liz McDowell is an assistant professor of nursing who also has a Masters of Divinity degree. Her primary nursing foci include mental health nursing and leadership. Prior to initiating this research project the co-investigators spent time discussing their thoughts, beliefs, and suppositions regarding spirituality, healings, and spiritual care. These discussions between the co-investigators continued throughout the data collection process in an attempt to bracket their own thoughts, feelings, and perceptions. Bracketing is the cognitive process of putting aside one's own beliefs so as not to make judgments about what one has heard (Streubert and Carpenter 2011). This bracketing allowed the co-investigators to remain open to the data as it was revealed.

The research protocol was reviewed and approved by the Lander University Institutional Review Board on 27 September 2016, prior to initiating data collection. The study was conducted in accordance with the Declaration of Helsinki and the researchers were committed to abide by the Federal Policy (Common Rule) for the Protection of Human Subjects (45 CFR 46). The institutional protocol number for this study is 2016-2.

The researchers knew the initial participants and the majority of the remaining participants $(n=15)$ were recruited through snowball referrals. One participant was contacted following an internet search. Sampling was purposive and included persons who had experienced healings, family of persons who had experienced healings, and persons who operated in the role of healers including pastors and a retired doctor. All of the participants included in this secondary research project were also part of the original research project. After giving their informed consent, participants were interviewed by the co-investigators in a place convenient and comfortable for the participants (in their homes, offices, restaurants, by telephone, or in the home of one of the researchers). All participants, ages 22 to 88 , practice the Christian faith and are residents of a southern region of the United States known as the 'Bible Belt'.

In the United States, the term 'Bible Belt' generally pertains to a region associated with fundamentalist Protestantism, puritanical mores, social conservatism, and a belief in the literal interpretation of the Bible (Sahl and Batson 2011; Brunn et al. 2011). This region differs from other regions because it has a distinct culture based on church involvement and religious ideology (Sahl and Batson 2011). The term, 'Bible Belt' was coined by H. L. Mencken, a journalist covering the Scopes 'monkey trial' in the 1920s. The region today stretches from northern Texas to western North Carolina, and from Mississippi to Kentucky (Brunn et al. 2011). The participants in this research project reside in South Carolina and Georgia. Table 1 demonstrates participant demographics. A total of 15 participants were interviewed before saturation was achieved.

A hermeneutic phenomenological approach was used in this research project. Open-ended questions facilitated the collection of the participants' experiences of healing. Open-ended questions allow participants to share their experiences in their own words rather than being forced into pre-established lines of thinking developed by the researchers (Streubert and Carpenter 2011). The interviews began with the primary open-ended request "to share your experiences with healing 
and healing miracles". Follow-up questions regarding the role of healthcare professionals provided narrative text that became the focus of this analysis: "Did healthcare professionals contribute to your healing experience by providing spiritual care? If so, describe how they contributed to your experience. If they did not, do you think there is a role for nurses and healthcare professionals in these types of healing experiences? If so, describe the role healthcare professionals could perform."

Table 1. Demographics of Participants

\begin{tabular}{cc}
\hline \multicolumn{2}{c}{ Age in Years } \\
\hline $22-35$ & 2 \\
$36-50$ & 2 \\
$51-60$ & 1 \\
$61-70$ & 5 \\
$71-80$ & 3 \\
$81-88$ & 2 \\
\hline Religious Preference \\
Baptist & 7 \\
Pentecostal Related & 4 \\
Methodist & 1 \\
Non-Denominational & 1 \\
Unspecified & 2 \\
\hline Occupation & \\
\hline Healthcare & 4 \\
Pastor & 3 \\
Professional (other) & 3 \\
Maintenance & 3 \\
Homemaker & 1 \\
Student & 1 \\
\hline Ethnicity & \\
\hline Caucasian & 14 \\
African & 1 \\
\hline Gender & \\
\hline Male & 8 \\
\hline Female & \\
\hline
\end{tabular}

Each interview lasted between 30 and 90 minutes and both co-investigators conducted all interviews. Following each interview, the transcripts were typed and reviewed for accuracy. The initial notes taken during the interviews and the typed transcripts are stored in a locked cabinet at the university and are only accessible to the co-investigators. The paper trail also includes notes taken during analysis of the data and grids demonstrating the theme discoveries. The objective of the paper trail is to illustrate as clearly as possible the evidence and thought processes that led to the conclusions (Streubert and Carpenter 2011). The analysis of the interview transcripts proceeded from a naïve reading of the transcripts to a clearer understanding of the transcripts emerging from repeated readings and data interpretation of the texts. This analysis began with the initial interview in November 2016 and was ongoing through the writing of this article. The interpretation of the whole involved reflecting on the initial reading along with the interpretive readings to ensure a comprehensive understanding of the findings which is known as the hermeneutic circle (Streubert and Carpenter 2011).

\section{Results}

In the analysis of the qualitative data, it was noted that both the spoken and unspoken responses of the participants provided a deeper understanding of their lived experiences of spiritual care by healthcare professionals during times of illness and healing. Out of 15 participants, only one, who was 
a retired general surgeon, talked about the role of doctors and nurses in providing spiritual care during the initial sharing of his story. The remaining participants did not mention any spiritual care provided by healthcare professionals during the initial sharing of their healing experiences. Specific follow-up questions regarding whether spiritual care was provided by healthcare professionals prompted positive responses from only half the participants. However, the majority of the participants agreed that there was indeed a need for spiritual care from healthcare professionals. It should be noted that three of the participants were nurses who shared their healing stories. However, these nurses also failed to mention spiritual care provided by healthcare professionals during the initial telling of their stories.

Prayer emerged as a prominent theme from the spoken stories of those participants who stated they received spiritual care from healthcare professionals. Even though the majority of participants had to be asked specifically about spiritual care from healthcare professionals before they mentioned prayer being provided by these healthcare workers, all of the participants mentioned self-prayer and/or prayer by others (family, churches, and pastors) in the initial telling of their healing experiences. To a much lesser degree, the participants identified support, comfort, kindness, and understanding as characteristics they desired in their healthcare professionals in providing spiritual care. Hesitancy toward providing spiritual care seemed to be a theme of the healthcare professionals themselves. A general lack of spiritual care by healthcare professionals, or lack of its importance to their healing stories, seemed evident by the unspoken responses.

\subsection{Prayer as Spiritual Care}

All participants mentioned prayer without prompting in the initial telling of their healing stories. However, the prayers were either self-prayers or prayers by churches, communities, friends, family, and pastors-not healthcare professionals. Even when participants were asked specifically about the spiritual care provided by healthcare professionals, prayer seemed to be their perception of what constituted spiritual care.

Four participants mentioned healthcare professionals praying for them during their experiences of illness and healing. J.M., a 74-year-old with numerous medical problems, stressed the importance of the role of prayer:

I have a lot of good doctors. This doctor called me at home several times. The doctors and nurses play a big role. I have had doctors and nurses pray for me before surgeries.

L.S., a practicing registered nurse ( $\mathrm{RN})$, described the role of prayer during her illness as being calming:

The most comfortable I felt was when I've had nurses come pray with me. I broke my arm. My doctor was doing open reduction. He asked to pray for me. I had an aortic valve replacement/aneurysm. I also had a male nurse pray for me. It was very calming. I was never scared during that surgery. Just having that doctor pray-same thing about the nurses.

One participant, R.H., who shared several healing stories, stated he had encountered many healthcare providers who believed in healing and prayer:

I've met so many, even when my wife had cancer. They were Christian. They believed in healing. They believed in prayer. My sister-in-law died of cirrhosis of the liver. Her doctor here in this county prayed for her.

J.C., a breast cancer survivor, stated she received no spiritual care from nurses but she had one doctor who would call her at home and tell her he was praying for her. L.N., a Baptist pastor, stated that he knew healthcare professionals who prayed with their patients. However, when sharing his own story, he did not mention being provided spiritual care by the healthcare team: 
I know there are doctors and nurses who will ask if they can pray. Prayer matters. I would welcome prayer from doctors and nurses.

\subsection{Support, Comfort, Kindness, and Understanding}

The majority of participants who stated they did not receive spiritual care from healthcare professionals during their illnesses and healings expressed an appreciation for its importance. J.M. stated that he "talks to a lot of people. If a nurse makes me feel good (some don't), it goes a long way. If you feel good, you have a better chance of being healed". L.S. stated that nurses providing spiritual care made her feel "comfortable, calm, and not scared". J.P., a college student, stated that it is important for healthcare professionals to build and maintain "positivity" in their patients.

M.T., an 86-year-old ovarian and uterine cancer survivor, believes the compassionate actions of the nurse can convey spiritual care:

Nurses do have a role. The first thing is to be kind and understanding. (I had many of those.) That almost tells what kind of person they are and in their way they are letting a person know they are a believer just by their kindness and the way they are taking care of a patient.

C.W., an oncology nurse and Hodgkin's survivor, was encouraged and supported by her doctor. She feels her healing experience can be a source of encouragement for her patients:

There is a role for the healthcare professional; it is very important. I'm trying to think. My doctor was very supportive. He encouraged me to go into oncology. He thought I would be encouraging to others-patients that you've cared for-that believed in their healing.

\subsection{Hesitancy to Provide Spiritual Care}

Four participants who shared their stories of healing were also healthcare professionals-three nurses and a retired surgeon. Although they expressed a belief in the importance of spiritual care, they expressed a hesitancy to perform the care. L.S., a nurse, even pondered if she would have been as "bold" as the nurses who provided spiritual care to her during her time of illness. C.W., another nurse, seemed more comfortable providing care but stressed the importance of gaining cues from her patients about the kind of care they need:

I pray with my patients and for my patients. I get a sense from my patients about prayer. I ask them about their families, career, and so forth. I get to know them and then they open up which leads to talking about the Lord. Sometimes I feel led to share my story, especially with young people who feel they are the only one. I will share with those in despair to provide hope. The Lord leads me. This is more of a ministry than a job.

M.S., a retired general surgeon, acknowledged the lack of education in medical school regarding how to provide spiritual care. Practicing continuous existential questioning and self-education, he eventually became more comfortable integrating spiritual care into his practice:

Fifty years ago, when I was in medical school, I was very interested in the mysteries of life. I was not born again, so I didn't know quite what to do with this. I felt that the life sciences were even more than what we could fathom .... I thought as a doctor there are going to be a lot we can't deal with-so there has to be more. But despite our best efforts, patients still are dying. This was a hole I didn't know how to fill ... . During my first few years of practice, my wife and I joined the Order of St. Luke. I still didn't quite know how to bring Christian healing into my practice...

He continued with a story about a man who had cancer and was very seriously ill. M.S. operated on the patient and found that his tumor was too large and complex to remove. The only thing he could offer was chemotherapy and radiation: 
I went to the patient's room and told the family. They were distraught. I didn't know what to do. In my mind I said, "God, I don't know what to do". Then I told the family, "He is alive and has a chance, and before he didn't". The family said, "Would you pray?" I didn't know what to say or do. But I started praying a beautiful prayer. I don't know where it came from ... After that I took all the healing courses I could. My wife came to work for me (she is a nurse). In 1994 I left my practice and opened up my own and it became known for its Christian practice. I gave the best surgery, but I also prayed, too ... Jesus can use doctors-doctors can pray. God gave us doctors to be used in healing ...

N.H., an 88-year-old retired Air Force and mill nurse, was hesitant in a different way. She was not hesitant to give spiritual care, but hesitant to talk about it. Although she is known in her community as a prayer warrior, she stated, "I think some people have the gift of healing. I don't think they should go around and talk about it". Her hesitancy to share her experiences of providing spiritual care was evident throughout the interview. However, she continued:

If the nurse knows the Lord, I think it will happen. I have worked with healthcare professionals who pray. I go in rooms to see how they are feeling. When at the mill, a man from personnel came to see me. He said, "You can't do anymore praying". I told him, "As long as I'm here I'm praying". They didn't fire me. We had prayer in the early mornings for a while. That got broken up.

\subsection{Lack of Spiritual Care}

What the participants failed to say, their unspoken responses, actually spoke volumes. When responding to the initial request to share their healing experiences, no one except the surgeon mentioned spiritual care by healthcare professionals. Although they often mentioned their families, friends, pastors, and churches praying, they did not mention spiritual care being given by healthcare workers until they were specifically asked. Even then, the care was sparse. Perhaps the most disturbing recollections came from J.C., a 71-year-old painter and retired police officer, who had numerous stories of illness and healing:

Every one of the nurses I asked said that they could not do it (pray). They've taken prayer out of school, and this, and that. But nothing keeps you from praying. I asked one black nurse and they said they would fire her. The chaplain, a black guy, was going to Augusta, Georgia. He came and talked to me ... I asked, "Do you want to pray?" He said, "I will pray for you". But he didn't pray then ... The nurses-I didn't knock them. Maybe they are scared of their jobs.

As a follow-up question J.C. was asked, "Did anyone in the hospital provide spiritual care?" Shaking his head, he replied: “No. In 2013 nobody did it. In 2009 nobody did it".

\section{Limitations}

The authors note several limitations to the study. First, the study is limited to participants who practice the Christian tradition living in a southeastern portion of the United States known as the Bible Belt. Therefore, there is no data from persons of other traditions or other religions, or even Christians from other geographical areas. In addition, the authors did not define "spiritual care" to the participants, therefore the care (or lack of care) described by the participants was limited to their perceptions of what the term meant.

\section{Conclusions}

Spirituality and spiritual care are elusive concepts that are difficult to define and are interpreted in various ways by individuals. Religious affiliations and cultural backgrounds affect the perception 
of spirituality and spiritual care. Both nursing theorists (Neuman and Fawcett 2002) and practicing nurses (Ledger 2005; Lane 2005; Dossey and Keegan 2016; Tiew and Creedy 2010; Boswell et al. 2013; Piotrowski 2013; Deal and Grassley 2012) recognize the importance of spirituality and spiritual care in treating the patient holistically. Our research study supports previous research that has shown that an individual healthcare worker's understanding of spirituality affects how the spiritual dimension is addressed or neglected in patient care. Our study also shows that an individual patient's understanding of spirituality and spiritual care affects how care or lack of care is perceived. Participants in this research study were not given a prescribed definition of spirituality or spiritual care and this individual understanding of spiritual care was evident in the responses of both the receivers and givers of care.

The Joint Commission on Accreditation of Healthcare Organizations (JCAHO) has a standard, RI.1.3.5, acknowledging the need for spirituality to be included in a client's plan of care. Results from Press Ganey National Inpatient data show a strong relationship between client satisfaction during a hospital stay and the hospital's care of the client's emotional and spiritual needs. The survey results indicate the impact and importance of holistic care, including various dimensions of a person's wellbeing (Clark et al. 2003). The participants in our research study confirmed the importance of receiving spiritual care although none of them reported receiving a spiritual assessment. Almost half of the participants stated they received no spiritual care from healthcare providers during the treatment for their illnesses.

Lowry and Conco (2002) conducted a focus group with 40 adult elders in the Appalachia area of the United States to explore the meaning of spirituality and its relationship to health status. The participants indicated the importance placed on spirituality including an increasing importance as they aged. Some elders agreed that health professionals should address spiritual needs by respect, kindness, thoughtfulness, compassion, and attention to their concerns. Reed (1991) conducted a study to determine patient preferences for spiritually related nursing interventions. The results of the study indicated patients prefer nurses to arrange visits with clergy, to facilitate an environment to allow spiritual expression, to provide time for interactions with family, and to engage in interactions with them as spiritual care interventions. Tanyi et al. (2006) conducted a phenomenological study to understand how women with end stage renal disease (ESRD) want nurses to address their spirituality. Four major themes suggestive of ways nurses could address spirituality emerged: "(a) displaying genuine caring; (b) building relationships and connectiveness; (c) initiating spiritual dialogue; and (d) mobilizing spiritual resources" (Tanyi et al. 2006, p. 534). The preferences for how spiritual care is delivered by nurses vary; however, the practices most often suggested by patients in research studies include: (a) compassionate care; (b) interactions with nurses, including "listening with the heart"; (c) environments conducive to spiritual practices; and (d) utilization of resources, such as chaplains (Crane-Okada 2007; Lowry and Conco 2002; Reed 1991).

The strategies for spiritual caregiving vary by professionals; however, similarities emerge as various research studies are examined. The perspective of bedside nurses was the aim of a research study conducted in a large university hospital in the southwestern part of the United States (Grant 2004). The hospital had been proactive in addressing patient spirituality and sponsored seminars on the spiritual dimension of care in medicine. A survey was mailed to 597 nurses with a response rate of $50 \%$. The most frequently employed or recommended spiritual care strategies by the respondents were: (a) holding a patient's hand; (b) listening; (c) laughing; (d) prayer; and (e) being present with the patient. Focus group interviews were conducted by Van Leeuwen et al. (2006) to gain insight into spiritual aspects of care of the nursing staff $(n=30)$. Open-ended questions were used to gather data. The results indicated that the basic spiritual care activities of the nurses participating in the study were the nurse's presence, listening, and respect. Spiritual care can involve a variety of approaches and must be individualized to meet the patients' needs. Unlike the previous research studies cited here, prayer was the predominant mode of spiritual care mentioned by the participants in our study. Prayer by and with doctors and nurses was viewed as spiritual care but this type of care 
was received to a much lesser degree than prayer provided by family, friends, pastors, and church communities. The fact that prayer was mentioned so often when our participants were asked about spiritual care reinforces the realization that the definition of spiritual care is somewhat limited in this population. Our participants mentioned to a much lesser degree the spiritual care interventions of support, comfort, kindness, and understanding which are more consistent with the broader concept of spiritual care mentioned by other researchers.

Patients/clients express the importance of receiving spiritual care from health care providers; however, many nurses report a lack of confidence and feelings of inadequacy in the provision of care related to spiritual needs (McClung et al. 2006; Swift et al. 2007; Tiew and Creedy 2010). Lack of education and expertise were reasons cited by nurses for feelings of incompetence delivering spiritual care (Skalla and McCoy 2006). Nurse Practitioners (NPs) in North Carolina were included in a study examining whether they included spiritual care and spiritual care interventions in their practices. Although the NPs reported a belief in the importance of spiritual care, they rarely incorporated spirituality in care plans (Hubbell et al. 2006). Half of the sample of 101 NPs felt their education in providing spiritual care was inadequate. Nurses who are comfortable with their own spirituality and those with experience are more likely to provide spiritual care to their patients due to an increase of confidence (Galek et al. 2007; Radwin 1998; Tiew and Creedy 2010; Deal and Grassley 2012). Our research supports these findings. It was interesting that even in the Bible Belt of the United States where our study was conducted, the healthcare professionals also seemed hesitant to offer or provide spiritual care. The retired surgeon in our study became more confident in providing spiritual care with increased education and experience.

Abu-Raiya et al. (2015) discuss Religion and Spirituality (RS) struggles of patients and categorize the struggles as supernatural struggles, interpersonal struggles, or intrapersonal struggles. Research has linked RS struggles with poor health and wellbeing. The authors address the importance of addressing these struggles after a spiritual assessment and to perform all spiritual care with sensitivity and a non-judgmental approach. Nurses who feel incompetent to provide spiritual care may hesitate to address RS struggles for fear of causing additional stress or conflict within patients.

A lack of understanding regarding what is considered spiritual care appears to be prevalent among both healthcare providers and patients. This disconnect contributes to the perception of patients who report a lack of spiritual care, although they acknowledge receiving compassion, caring, and respect from nursing and medical staff. Researchers have examined the provision of spiritual care, including the perception of both patients and healthcare providers for decades. The continued hesitancy of healthcare providers to provide spiritual care and the lack of spiritual care perceived by patients brings to question the progress achieved in this area. A literature review indicates that nurses feel incompetent to provide spiritual care; however, they routinely provide caring, patient-centered care with respect and compassion. Education is indicated for both patients and healthcare providers on the topics of spirituality, spiritual assessments, and spiritual care strategies. Additional research is needed to further define the concepts related to spirituality and spiritual caregiving. Including spirituality-related content into curricula of nursing and related health fields would provide new graduates greater insight in their role as spiritual caregivers. Providing accessible continuing educational sessions on spiritual care through various mechanisms could strengthen the active workforce of today's healthcare environment and would enhance the provision of holistic, patient-centered care.

Author Contributions: Liz McDowell and Robbie Madden South conceived and designed the study; Liz McDowell and Robbie Madden South interviewed the participants, transcribed and analyzed the data, and wrote the paper.

Conflicts of Interest: The authors declare no conflict of interest.

\section{References}

Abu-Raiya, Hisham, Kenneth I. Pargament, and Julie J. Exline. 2015. Understanding and Addressing Religious and Spiritual Struggles in Health Care. Health and Social Work 40: e126-34. [CrossRef] 
Boswell, Carol, Sharon B. Cannon, and Joyce Miller. 2013. Students' Perceptions of Holistic Nursing Care. Nursing Education Perspective 34: 329-33. [CrossRef]

Brunn, Stanley D., Gerald R. Webster, and J. Clark Archer. 2011. The Bible Belt in a Changing South: Shrinking, Relocating, and Multiple Buckles. Southeastern Geographer 51: 513-49. [CrossRef]

Canfield, Christina, Debi Taylor, Kimberly Nagy, Claire Strauser, Karen VanKerkhove, Stephanie Wills, Patricia Sawicki, and Jeanne Sorrell. 2016. Critical Care Nurses' Perceived Need for Guidance in Addressing Spirituality in Critically Ill Patients. American Journal of Critical Care 25: 206-11. [CrossRef] [PubMed]

Clark, Paul Alexander, Maxwell Drain, and Mary P. Malone. 2003. Patient Centeredness: Addressing patients' Emotional and Spiritual Needs. Joint Commission Journal on Quality and Safety 29: 659-70. [CrossRef]

Crane-Okada, Rebecca. 2007. A Compass for the Cancer Journey: Scientific, Spiritual, and Practical Directives. Oncology Nursing Forum 34: 945-55. [CrossRef] [PubMed]

Deal, Belinda, and Jane S. Grassley. 2012. The Lived Experience of Giving Spiritual Care: A Phenomenological Study of Nephrology Nurses Working in Acute and Chronic Hemodialysis Settings. Nephrology Nursing Journal 39: 471-82. [PubMed]

Dossey, Barbara Montgomery, and Lynn Keegan. 2016. Holistic Nursing: A Handbook for Practice. Burlington: Jones and Bartlett.

Ebrahimi, Hossein, Hossein Namdar Areshtanab, Mohammad Asghari Jafarabadi, and Soraya Golipoor Khanmiri. 2017. Health Care Providers' Perception of Their Competence in Providing Spiritual Care for Patients. Indian Journal of Palliative Care 23: 57-61. [PubMed]

Galek, Kathleen, Kevin J. Flannelly, Harold G. Koenig, and Rev. Sarah L. Fogg. 2007. Referrals to Chaplains: The Role of Religion and Spirituality in Healthcare Settings. Mental Health, Religion E Culture 10: 363-77.

Grant, Don. 2004. Spiritual Interventions: How, When, and Why Nurses Use Them. Holistic Nursing Practice 18: 36-41. [CrossRef] [PubMed]

Hodge, David R., and Violet E. Horvath. 2011. Spiritual Needs in Healthcare Settings: A Qualitative Meta-Synthesis of Clients' Perspectives. Social Work 56: 306-16. [CrossRef] [PubMed]

Hodge, David, and Robert Wolosin. 2014. Spiritual Needs and Satisfaction with Service Provision: Mediating Pathways among a National Sample of Hospital Inpatients. Social Work Research 38: 135-42. [CrossRef]

Hubbell, Sara L., Elizabeth K. Woodard, Debra J. Barksdale-Brown, and Jill S. Parker. 2006. Spiritual Care Practices of Nurse Practitioners in Federally Designated Nonmetropolitan Areas of North Carolina. Journal of the American Academy of Nurse Practitioners 18: 379-85. [CrossRef] [PubMed]

Lane, Mary Rockwood. 2005. Creativity and Spirituality in Nursing: Implementing Art in Healing. Holistic Nursing Practice 19: 122-25. [CrossRef] [PubMed]

Ledger, Sylvia Dianne. 2005. The Duty of Nurses to Meet Patients' Spiritual and/or Religious Needs. British Journal of Nursing 14: 220-25. [CrossRef] [PubMed]

Lowry, Lois W., and Diana Conco. 2002. Exploring the Meaning of Spirituality with Aging Adults in Appalachia. Journal of Holistic Nursing 20: 388-402. [CrossRef] [PubMed]

McClung, Emily, Daniel H. Grossoehme, and Ann F. Jacobson. 2006. Collaborating with Chaplains to Meet Spiritual Needs. MEDSURG Nursing 15: 147-56. [PubMed]

Mowdy, Roberta. 2006. Spirituality and Health Care. In Nursing Now: Today's Issues, Tomorrow's Trends, 4 th ed. Edited by Joseph T. Catalana. Philadelphia: F. A. Davis Company, pp. 393-407.

Betty Neuman, and Jacqueline Fawcett, eds. 2002. The Neuman Systems Model, 4th ed. Upper Saddle River: Prentice Hall.

O'Brien, Mary Elizabeth. 2008. Spirituality in Nursing: Standing on Holy Ground, 3rd ed. Sudbury: Jones and Bartlett.

Piotrowski, Linda. 2013. Advocating and Educating for Spiritual Screening Assessment and Referrals to Chaplains. Omega 67: 185-92. [CrossRef] [PubMed]

Puchalski, Christina M., Robert Vitillo, Sharon K. Hull, and Nancy Reller. 2014. Improving the Spiritual Dimension of Whole Person Care: Reaching National and International Consensus. Journal of Palliative Medicine 17: 642-56. [CrossRef] [PubMed]

Radwin, Laurel E. 1998. Empirically Generated Attributes of Experience in Nursing. Journal of Advanced Nursing 27: 590-95. [CrossRef] [PubMed]

Reed, Pamela G. 1991. Preferences for Spiritually Related Nursing Interventions Among Terminally Ill and Non-Terminally Ill Hospitalized Adults and Well Adults. Applied Nursing Research 4: 122-28. [CrossRef] 
Sahl, Allison H., and Christie D. Batson. 2011. Race and Religion in the Bible Belt: Parental Attitudes Toward Interfaith Relationships. Sociological Spectrum 31: 444-65. [CrossRef]

Skalla, Karen A., and J. Patrick McCoy. 2006. Spiritual Assessment of Patients with Cancer: The Moral Authority, Vocational, Aesthetic, Social, and Transcendent Model. Oncology Nursing Forum 33: 745-51. [CrossRef] [PubMed]

South, Robbie Madden. 2017. An Example of Teaching Patient-Centered Care: Assessing Spirituality. In Neuman Systems Model: Celebrating Academic-Practice Partnerships. Edited by Sarah Beckman and Jacqueline Fawcett. Fort Wayne: Neuman Trustee Group, Inc., p. 63.

Streubert, Helen, and Dona Rinaldi Carpenter. 2011. Qualitative Research in Nursing: Advancing the Humanistic Imperative, 5th ed. Philadelphia: Wolters Kluwer/Lippincott Williams \& Wilkins.

Swift, Chris, Sara Calcutawalla, and Rosie Elliot. 2007. Nursing Attitudes towards Recording of Religious and Spiritual Data. British Journal of Nursing 16: 1279-82. [CrossRef] [PubMed]

Taheri-Kharameh, Zahra, Hamid Asayesh, Fatemeh Sharififard, and Alireza Alinoori. 2016. Attitude toward Spirituality, Spiritual Care, and Its Relationship with Health among Intensive Care Nurses. Health, Spirituality and Medical Ethics 3: 25-29.

Tanyi, Ruth A., Recine Ann C. Gentry, Joan Stehle Werner, and Rita A. Sperstad. 2006. Perceptions of Incorporating Spirituality into Their Care: A phenomenological Study of Female Patients on Hemodialysis. Nephology Nursing Journal 33: 532-38.

Tanyi, Ruth A., Monica McKenzie, and Cynthia Chapek. 2009. How Family Practice Physicians, Nurse Practitioners, and Physician Assistants Incorporate Spiritual Care into Practice. Journal of the American Academy of Nurse Practitioners 21: 690-97. [CrossRef] [PubMed]

Taylor, Elizabeth Johnston. 2002. Spiritual Care: Nursing Theory, Research, and Practice. Upper Saddle River: Prentice Hall.

Tiew, Lay Hwa, and Debra K. Creedy. 2010. Integration of Spirituality in Nursing Practice: A Literature Review. Singapore Nursing Journal 37: 15-22.

Van Leeuwen, René, Lucas J. Tiesinga, Doeke Post, and Henk Jochemsen. 2006. Spiritual Care: Implications for Nurses' Professional Responsibility. Journal of Clinical Nursing 15: 875-84. [CrossRef] [PubMed]

Winslow, Gerald R., and Betty Wehtje Winslow. 2003. Examining the Ethics of Praying with Patients. Holistic Nursing Practice 17: 170-77. [CrossRef] [PubMed] 